\title{
HLA-DP and coeliac disease: family and population studies
}

C Caffrey, G A Hitman, M J Niven, P G Cassell, P Kumar, L Fry, P Mackintosh, R Gallagher, C Feighery, D Weir, J A Sachs shown tighter associations of $\mathrm{CD}$ with the extended haplotypes HLA-A1-B8-DR3-SCO1 and HLA-B44-DR7-FC31 ${ }^{12}$; and Hitman et al ${ }^{13}$ and Gorski et $a l^{14}$ have shown preferential allelic associations of CD based on serological specificities, restriction fragment length polymorphisms, and sequence variation of the HLA-DR and DQ genes. Furthermore, the extended HLA-DR3 haplotype is also found in other autoimmune diseases - for instance, insulin dependent diabetes mellitus and another gluten sensitive disorder, dermatitis herpetiformis. ${ }^{13}$

Available evidence therefore indicates that the genetic component in CD is due to determinants at more than one locus. Based on monozygotic twin concordance data, the empirical sibling risks, and HLA gene sharing in siblings with CD Rotter and Landaw have estimated that the described associations with HLA-A, B, C, and DR account for only $30 \%$ of the genetic component in CD. ${ }^{1}$ It is thus likely that other loci are involved in this multifactorial disease, and indeed recently HLA-DP genes have been implicated. ${ }^{15} 16$

The purpose of this study was (i) to extend our original observations ${ }^{15}$ of the association of a Bgl II polymorphism of the DP $\alpha$ gene with CD to two other DR3 related diseases: insulin dependent diabetes mellitus and dermatitis herpetiformis; (ii) to examine segregation of the $\mathrm{DP} \alpha$ polymorphism in families with $\mathrm{CD}$; and (iii) to correlate polymorphisms of the DP $\alpha$ and DP $\beta$ genes in CD.

Coeliac disease (CD) is characterised by damage to the intestinal mucosa with consequent malabsorption, which is reversible on withdrawal from the diet of the cereal protein gluten. A genetic component to this disease is well established by the high rate of concordance in monozygotic twins (70-100\%) and an increased clustering in families $(5-20 \%$ of first degree relatives have evidence of partial villous atrophy established by small bowel biopsy). ${ }^{1}$ Part of this genetic component in $\mathrm{CD}$ has been mapped to the major histocompatibility complex (MHC) located on the short arm of chromosome 6 , with $95 \%$ of pairs of siblings with coeliac disease sharing one or more MHC haplotypes. ${ }^{2}$

The human MHC includes three subregions: class I (HLA-A, B, C), class III (properdin Bf, complement $\mathrm{C} 2$ and $C 4$, and 21 hydroxylase) and class II (HLA-DR, DQ, and DP), although many other genes have now been identified within this complex..$^{3-5}$ The first associations between the MHC and CD to be found were with HLA-Al and HLA-B8; $;{ }^{67}$ subsequently closer associations were found with HLA-DR3, HLA-DR7, and HLA-DQw2. ${ }^{28-11}$ The population approach has been extended by Alper and colleagues who have

\section{Patients and methods}

All patients studied were unrelated white British, many of whom had been previously typed for HLA class I and class II antigens. ${ }^{13}$ Ninety nine control subjects were serially selected from staff at the London Hospital Medical College. None had a personal or family history of $\mathrm{CD}$, dermatitis herpetiformis, or insulin dependent diabetes mellitus.

\section{PATIENTS WITH CD}

(a) Population study. Sixty five patients were serially selected from clinics at either St Bartholomew's Hospital, London, or Queen Elizabeth Hospital for Children, Hackney. All had had an intestinal biopsy showing subtotal withdrawal of gluten from the diet. All patients who also had dermatitis herpetiformis were excluded.

(b) Family study. Seven families with at least two members with CD (a total of 49 people, Fig 1), were recruited from the clinics at St James villous atrophy which was reversed after the 
Hospital, Dublin, Queen Elizabeth Hospital, Birmingham, the Luton and Dunstable Hospital, and St Bartholomew's Hospital. Siblings and parents who did not have clinical symptoms suggesting CD were classified as healthy for this study. All but family 5 in this study were of Irish ancestry.

\section{PATIENTS WITH DERMATITIS}

HERPETIFORMIS

Sixty two patients were serially selected from the dermatology clinic at St Mary's Hospital, London, who had spontaneous subepidermal blisters and deposits of $\operatorname{IgA}$ in the papillary dermis of unaffected skin. All cases of linear IgA disease were excluded.

\section{PATIENTS WITH INSULIN DEPENDENT DIABETES}

Seventy eight patients with insulin dependent diabetes mellitus were recruited from the diabetic clinic at the London Hospital as previously described. ${ }^{13}$

\section{EXPERIMENTAL METHODS}

DNA was extracted from whole blood samples and studied by Southern blot hybridisation methods ${ }^{13}$ using the following probe-enzyme combinations: (i) a cDNA DP $\alpha$ probe (kindly donated by $\mathrm{J}$ Trowsdale, Imperial Cancer Research Fund, London) with the restriction enzyme Bgl II; (ii) a cDNA DP $\beta$ probe (from the Xth HLA International Workshop) with the restriction enzyme Msp I. Gene sequences were detected by autoradiography and sized by comparison with Hind III digested lambda phage and an internal laboratory standard.

\section{STATISTICS}

Statistical comparisons were made using $\chi^{2}$ analysis and the method of Woolf to derive the relative risk and $95 \%$ confidence intervals. ${ }^{17}$

\section{Results}

DP $\alpha$ POPULATION STUDY

Using a $\mathrm{DP} \alpha$ probe and the restriction enzyme Bgl II, two polymorphic fragments were identified, sized $3 \cdot 5$ and $2 \cdot 2 \mathrm{~kb}$. There was slight size variation of the $3.5 \mathrm{~kb}$ fragment (see Fig 2); a similar size variation was found in the corres-

TABLE I HLA-DPa polymorphism (Bgl II) in patients with coeliac disease, dermatitis herpetiformis, and insulin dependent diabetes and control subjects

\begin{tabular}{|c|c|c|c|c|}
\hline & No & $\begin{array}{l}D P \alpha 3 \cdot 5 \mathrm{~kb} \\
\text { positive (\%) }\end{array}$ & $\begin{array}{l}\text { Relative } \\
\text { risk }\end{array}$ & $\begin{array}{l}95 \% \text { confidence } \\
\text { intervals }\end{array}$ \\
\hline \multirow{3}{*}{$\begin{array}{l}\text { Control subjects } \\
\text { Coeliac disease } \\
\text { Dermatitis } \\
\text { herpetiformis } \\
\text { Insulin dependent } \\
\text { diabetes mellitus }\end{array}$} & $\begin{array}{l}99 \\
65\end{array}$ & $\begin{array}{l}34 \\
75^{\star}\end{array}$ & $5 \cdot 9$ & $2 \cdot 9$ to $11 \cdot 8$ \\
\hline & 62 & $57 \dagger$ & $2 \cdot 5$ & $1 \cdot 3$ to 4.8 \\
\hline & 78 & $44 \ddagger$ & 1.5 & 0.8 to 2.7 \\
\hline
\end{tabular}

$\chi^{2}$ analysis of disease $v$ controls: ${ }^{\star} \mathrm{p}<0.001, \mathrm{tp}=0.01$, fnot significant. ponding subjects using a second enzyme, Taq 1 (data not shown). This size difference probably reflects the presence of a hypervariable region. Table I shows the frequency of the DP $\alpha 3.5 \mathrm{~kb}$ band in the three patient groups and in control subjects. There is a pronounced association with $\mathrm{CD}(75 \%$ compared to $34 \%$ in controls, $\mathrm{p}<0.001)$ and a weaker association with dermatitis herpetiformis $(57 \% v 34 \%, \mathrm{p}=0.01)$, but no association with insulin dependent diabetes mellitus. The presence of DP $\alpha .5 \mathrm{~kb}$ did not correlate with the presence of DR3 or DR7 in the control or patient populations.

\section{DP $\alpha$ FAMILY STUDY}

In six of the seven families there were at least two siblings with CD. Examining the two eldest affected siblings in each of these families and looking at the two generations in family 3 , three siblings are HLA identical (families 2, 3 (FIII), and 5), two are haploidentical (families 3 (FII) and 6), and two are non-identical (families 1 and 4). Only four of the seven families $(1,3,6$, and 7$)$ proved to be informative for segregation of HLA-DP $\alpha 3.5 \mathrm{~kb}$ with HLA serological typing. The DP $\alpha$ Bgl II restriction fragment length polymorphism did not consistently segregate with any particular haplotype (eg HLA-A1-B8DR3, although present with $\mathrm{DP} \alpha 3 \cdot 5$ on paternal haplotype in family 7 there are four other cases where it is in linkage with $\mathrm{DP} \alpha 2 \cdot 2$ (Table II)). One definite recombination (FII-2 in family 7) between HLA-DP and HLA-DR was found in this study and also one probable recombination (FII-1 in family 4).

\section{DP $\beta$ POPULATION STUDY}

Using a DP $\beta$ probe and the restriction enzyme Msp I the distribution of the four polymorphic fragments, sized $4 \cdot 9,3 \cdot 0,1 \cdot 8$, and $1 \cdot 1 \mathrm{~kb},{ }^{18}$ was studied in patients with $C D$ and control subjects (Fig 3). The principal findings (Table III) are an increase in frequency in $C D$ of the $4.9 \mathrm{~kb}$ fragment $(51 \%$ compared to $11.5 \%$ of controls; $\mathrm{p}<0.001$ ) with a decrease in frequency of the DP $\beta 1 \cdot 1 \mathrm{~kb}$ fragment (63\% compared to $94 \%$ in controls; $p=0 \cdot 002$ ).

The coinheritance of both the DP $\alpha 3.5 \mathrm{~kb}$ and DP $4.9 \mathrm{~kb}$ fragments was examined in 48 patients with $C D$ and in 42 control subjects (Table IV); most of those with DP $\beta 4.9 \mathrm{~kb}$ also possessed DP $\alpha \cdot 5(22 / 27,81 \%)$, whereas there

TABLE II Segregation of $D P \alpha 3.5$ with class I (HLA-A and $H L A-B)$ and class II $(H L A-D R)$ antigens

\begin{tabular}{|c|c|c|}
\hline & $D P \alpha 3 \cdot 5$ & $D P \alpha 2.2$ \\
\hline Family 1 & A29-B44-DR7 & $\begin{array}{l}\text { A1-B8-DR3 } \\
\text { A2-B51-DR2 } \\
\text { A2-B62-DR4 }\end{array}$ \\
\hline Family 3 & A11-B44-DR7 & $\begin{array}{l}\text { A2-B50-DR4 } \\
\text { A1-B8-DR3 } \\
\text { A1-B8-DR7 }\end{array}$ \\
\hline Family 6 & $\mathrm{~A} 2-\mathrm{B} 12-\mathrm{DR} 2$ & $\begin{array}{l}\text { A1-B8-DR3 } \\
\text { A2-B13-DR7 } \\
\text { A1-B37-DR6 }\end{array}$ \\
\hline Family 7 & $\begin{array}{l}\text { A1-B8-DR3 } \\
\text { A2-B14-DR3 }\end{array}$ & $\begin{array}{l}\text { A29-B12-DR7 } \\
\text { A1-B8-DR3 }\end{array}$ \\
\hline
\end{tabular}

$\mathrm{DP} \alpha 3.5$ and DP $\alpha 2 \cdot 2$ are two DP $\alpha$ allelic fragments detected by Southern blot hybridisation methods and the restriction enzyme Bgl II. ${ }^{15}$ is Family numbers refer to pedigrees as set out in Figure 1. 

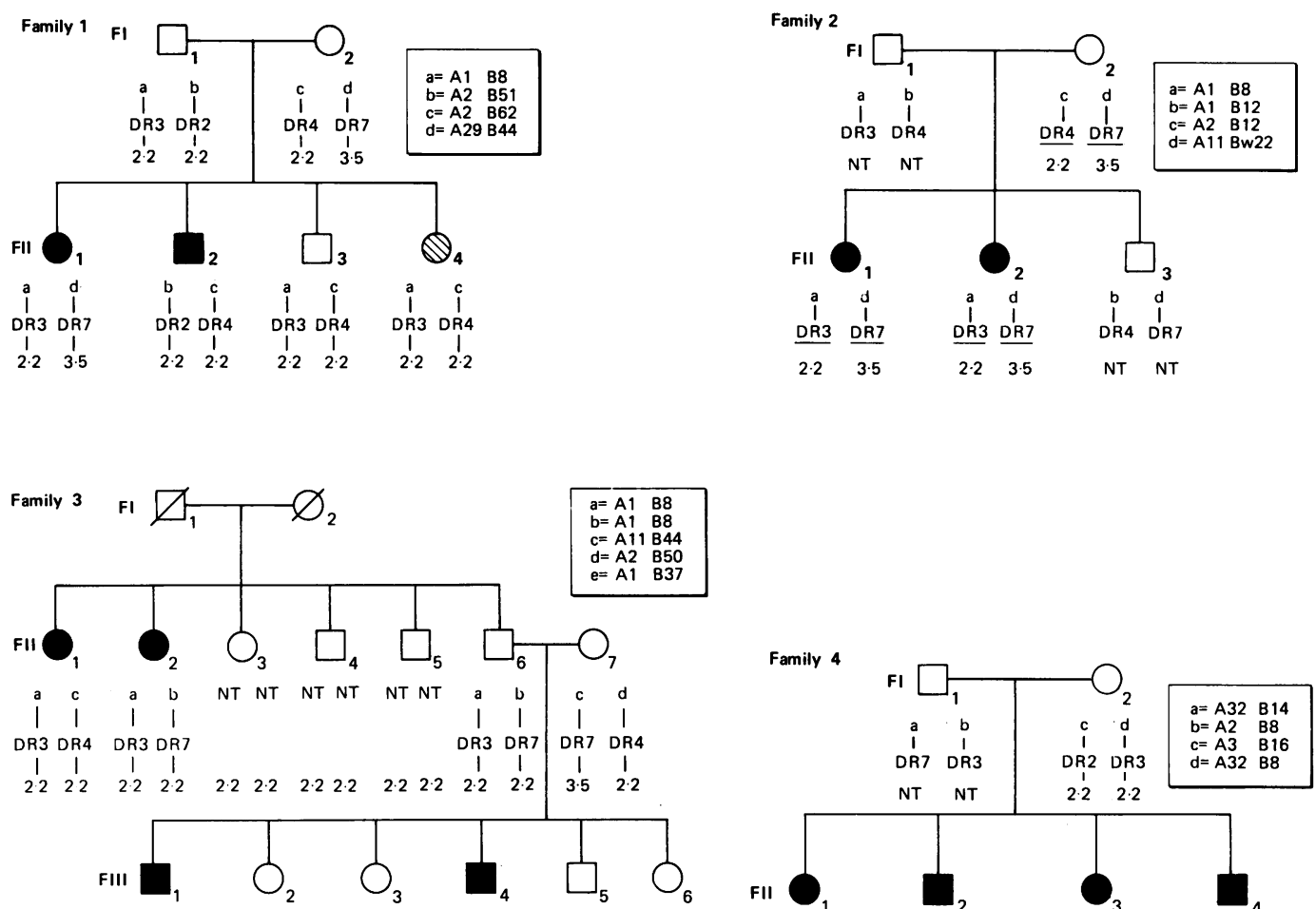

$\begin{array}{cccccccccccc}\text { a } & c & a & c & a & c & a & c & a & c & a & c \\ 1 & 1 & 1 & 1 & 1 & 1 & 1 & 1 & 1 & 1 \\ D R 3 & D R 7 & \text { DR3 } & \text { DR7 } & \text { DR3 } & \text { DR7 } & \text { DR3 } & \text { DR7 } & \text { DR3 } & \text { DR7 } & \text { DR3 } & \text { DR7 }\end{array}$

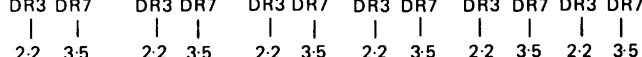

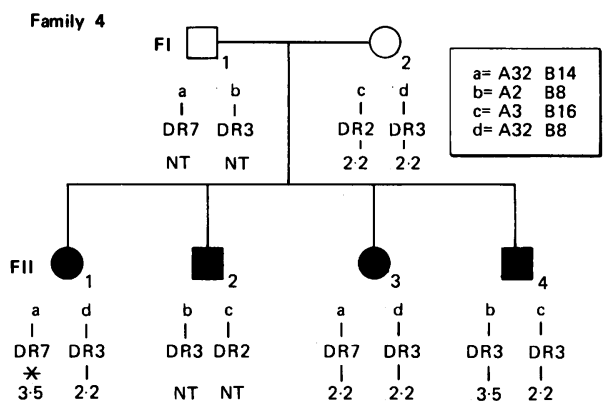

Family 5

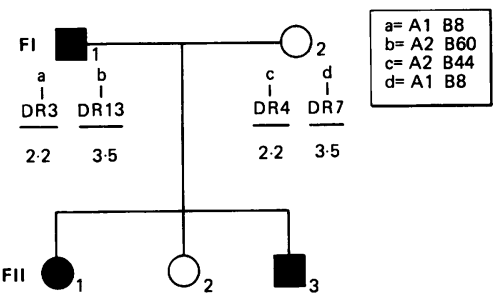

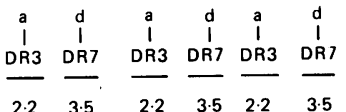

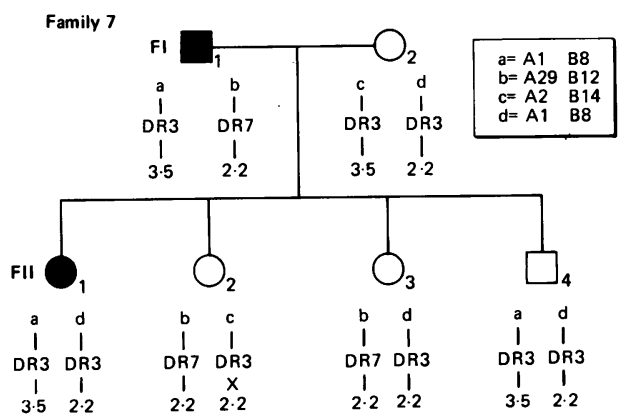

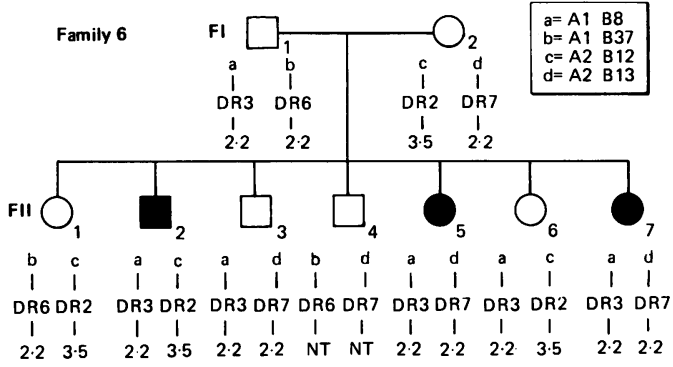

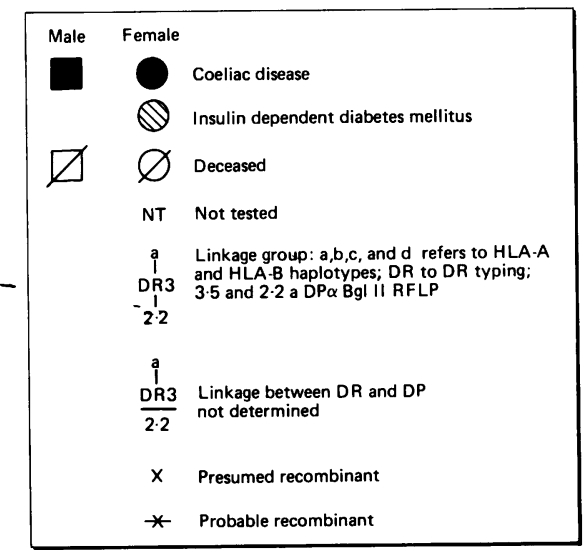

Figure 1: Pedigree analysis. $R F L P=$ restriction fragment length polymorphism.

was a significant number who possessed $\mathrm{DP} \alpha 3 \cdot 5$ but not DP $\beta 4.9 \mathrm{~kb}(25 / 47,53 \%)$, a combination which was increased in patients with $\mathrm{CD}(37 \%$, $18 / 48$ compared to $17 \%, 7 / 42$ in control subjects, $\mathrm{p}=0.05)$.

\section{Discussion}

We have previously described an association of $\mathrm{CD}$ with the $\mathrm{Bgl}$ II $\mathrm{DP} \alpha 3.5 \mathrm{~kb}$ polymorphism ${ }^{15}$ and from our current studies we conclude that there is a similar but weaker association in 


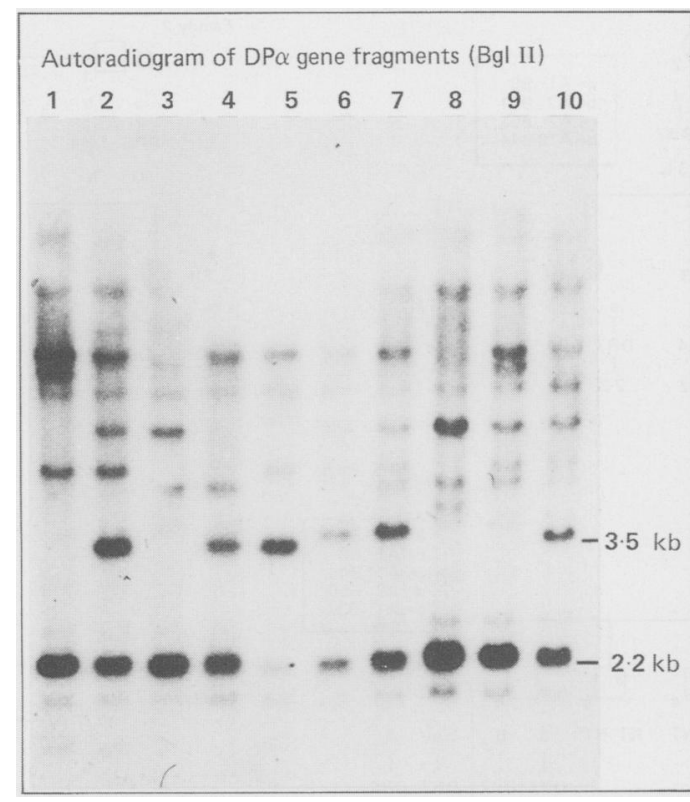

Figure 2: Bgl II DP $\alpha$ autoradiogram. DNA was extracted from whole blood samples, digested with the restriction enzyme Bgl II, and studied by Southern blot hybridisation methods and a $c D N A D P \alpha$ probe. $D P \alpha 3 \cdot 5$ and $2 \cdot 2$ are indicated.

dermatitis herpetiformis but not in insulin dependent diabetes. We now show that in $\mathrm{CD}$ (a) the DP $\alpha$ polymorphism does not preferentially segregate with a particular HLA-DR/DQ phenotype in patients or controls, (b) there are associations with a DP $\beta$ polymorphism, and (c) there is an interrelationship between the DP $\alpha$ and DP $\beta$ polymorphisms.

In our extended $\operatorname{CD}(n=65)$ and control $(n=$ 99) panels we again observed the increased frequency of the $3.5 \mathrm{~kb}$ fragment in CD first detected by Niven et al. ${ }^{15}$ Simultaneously, Howell et $a l$, using the restriction enzyme Xba I and a $\mathrm{DP} \alpha$ probe, also reported an association of a 19 $\mathrm{kb}$ fragment with CD being present in $84 \%$ of 19 patients compared to $36 \%$ of 11 controls. ${ }^{16}$

With the DP $\beta$ probe and the restriction enzyme Msp I, the $4.9 \mathrm{~kb}$ fragment was found in

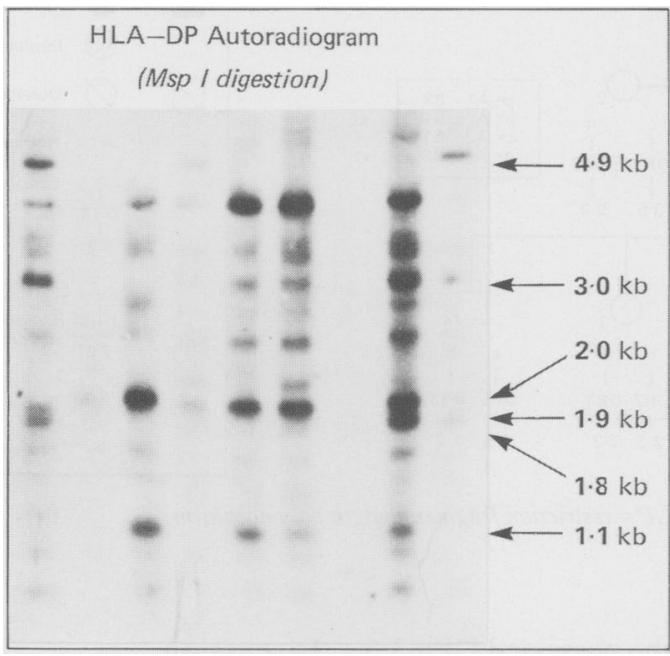

Figure 3: Msp I DP $\beta$ autoradiogram. DNA was extracted from whole blood samples, digested with the restriction enzyme Msp I, and studied by Southern blot hybridisation methods and a $c D N A D P \beta$ probe. Sizes of fragments are indicated.
TABLE III HLA-DP及(Msp I) polymorphism in patients with coeliac disease and healthy controls (figures in parentheses are numbers

\begin{tabular}{|c|c|c|c|c|}
\hline \multirow{2}{*}{$\begin{array}{l}D P \beta \\
\text { fragment } \\
(\mathrm{kb})\end{array}$} & \multicolumn{2}{|l|}{ Positive (\%) } & \multirow[b]{2}{*}{$\begin{array}{l}\text { Relative } \\
\text { risk }\end{array}$} & \multirow[b]{2}{*}{$\begin{array}{l}95 \% \text { confidence } \\
\text { intervals }\end{array}$} \\
\hline & $\begin{array}{l}\text { Control } \\
\text { subjects }\end{array}$ & $\begin{array}{l}\text { Patients with } \\
\text { coeliac disease }\end{array}$ & & \\
\hline $\begin{array}{l}4.9 \\
3 \cdot 0 \\
1 \cdot 8 \\
1 \cdot 1\end{array}$ & $\begin{array}{l}11 \cdot 5(6 / 52) \\
92(33 / 36) \\
27(9 / 33) \\
94(48 / 51)\end{array}$ & $\begin{array}{l}51(30 / 59)^{\star} \\
82(43 / 52) \dagger \\
33(14 / 42) \dagger \\
63(33 / 52) \ddagger\end{array}$ & $\begin{array}{l}9 \cdot 0 \\
0 \cdot 5 \\
1 \cdot 3 \\
0 \cdot 1\end{array}$ & $\begin{array}{l}3.3 \text { to } 24 \cdot 1 \\
0 \cdot 1 \text { to } 1 \cdot 8 \\
0.5 \text { to } 3.6 \\
0.03 \text { to } 0.39\end{array}$ \\
\hline
\end{tabular}

${ }^{\star} \chi^{2}=16.7 ; p<0.001$. $\nmid$ Not significant. $\neq \chi^{2}=13.9 ; p=0.002$.

DP $4.9 \mathrm{~kb}, 3.0 \mathrm{~kb}, 1.8 \mathrm{~kb}$, and $1.1 \mathrm{~kb}$ are non-allelic fragments of DP $\beta$ detected by Southern blot hybridisation methods and the restriction enzyme Msp I. ${ }^{18}$ Individuals in which the presence of a fragment was equivocal were excluded from the analysis; thus the number of individuals studied for each DP $\beta$ fragment is not the same.

TABLE IV Correlation of $D P \alpha 3.5 \mathrm{~kb}$ and $D P \beta 4.9 \mathrm{~kb}$ polymorphism in control subjects and patients with coeliac disease (percentages in parenthesis)

\begin{tabular}{lcccl}
\hline$D P \alpha 3 \cdot 5, D P \beta 4 \cdot 0$ & ++ & +- & -+ & -- \\
\hline $\begin{array}{l}\text { Control subjects }(\mathrm{n}=42) \\
\text { Patients with coeliac disease } \\
(\mathrm{n}=48)\end{array}$ & $3(7)$ & $7(17)$ & $2(5)$ & $30(71)$ \\
\hline
\end{tabular}

$++=\mathrm{DP} \alpha 3.5$ positive $\mathrm{DP} \beta 4.9$ positive; $+-=\mathrm{DP} \alpha 3.5$ positive $\mathrm{DP} \beta 4.9$ negative; $-+=\mathrm{DP} \alpha 3.5$ negative $\mathrm{DP} \beta 4.9$ positive; DP $\beta 4.9$ negative; $-+=D P \alpha 3.5$ negative
$--=D P \alpha 3.5$ negative DP 4.9 negative.

half our patients compared to just over $10 \%$ of controls. Similarly, Howell et al identified a $4 \mathrm{~kb}$ fragment with the enzyme Rsa I which was increased in CD patients, especially those with the DR3-DQw2 phenotype. ${ }^{16}{ }^{19}$ Together with their limited DP $\alpha$ data they concluded that the $\mathrm{DP} \alpha$ and DP $\beta$ restriction fragment length polymorphisms (RFLPs) associated with CD were in linkage disequilibrium with the corresponding DR and DQ polymorphisms, particularly DR3$\mathrm{DQw} 2$. In our population data there was no correlation between the DP $\alpha$ RFLPs and any particular DR/DQ phenotype, nor did our family studies show segregation of $\mathrm{DP} \alpha 3.5$ with specific DR3 or DR7 haplotypes. Furthermore, we observed recombinants between the HLADR and DP regions in two of our families. This latter observation is to be expected as when the DP region was first defined (by the cellular primed lymphocyte typing method) no linkage disequilibrium between the DP and DQ/DR regions could be shown..$^{20} \mathrm{We}$ therefore conclude that the susceptibility gene associated with the DP region is different from those identified in the $D R / D Q$ region.

Two groups have attempted to correlate DP typing with RFLP analysis. ${ }^{1821}$ Of relevance to the present study, Hyldig-Nielsen had previously described the same $\mathrm{DP} \alpha 3.5 \mathrm{~kb}$ and the DP $\beta$ Msp I polymorphisms that we studied and correlated those RFLPs with DP primed lymphocyte typing (PLT) in healthy Danish whites. ${ }^{18}$ Although there is a correlation of DP typing with DP $\alpha$ Bgl II and Msp I DP $\beta$ RFLPs, the latter method cannot be used for the accurate prediction of DP PLT and therefore differences in the distribution of PLT determined DPspecificities between patients with $C D$ and control subjects cannot be inferred.

Thus we have now shown at least three independent HLA-associated susceptibility alleles linked to $\mathrm{CD}$, two located in the $\mathrm{DR} / \mathrm{DQ}$ 
region 111314 and one located in the DP region. ${ }^{15}$ Whether the three alleles (or their products) interact to engender susceptibility to $C D$ or whether they represent independent but additive susceptibility genes remains to be determined. Preliminary evidence from de Koster and colleagues, ${ }^{22}$ that the DP antigen helps to present processed DR3 antigen to $T$ helper cells provides a possible mechanism for interaction between the products of these two HLA subregions and hence a model for disease susceptibility. However, it should be noted that DP $\alpha 3.5 \mathrm{~kb}$ is not necessary for $C D$ within families: for instance, in family 6, of three siblings with CD only FII-2 possesses DP $\alpha 3.5 \mathrm{~kb}$. Furthermore, in our limited family study two affected sibling pairs are non-HLA identical (family 1 and family 4 ); in previous reports only three out of 72 similar sibling pairs have been found to be HLA-nonidentical. ${ }^{2}$ The fact that no one genetic marker has ever been found to be present in all patients with $C D$ and that non-HLA identical sib pairs with $C D$ exist raises the possibility that different susceptibility alleles can be separately associated with $C D$ and each can lead to disease, or that the susceptibility allele of a given haplotype can be inherited as part of a second haplotype within the family. Alternatively, susceptibility to $C D$ may be dependent on the summated genetic load arising from alleles at a number of loci. As a result of such a threshold effect, combinations of alleles, differing between families and even individuals within families, may ultimately result in susceptibility to $C D$.

We thank Professor J Walker-Smith and Dr S Jain for access to their patients and the Medical Research Council (Ireland) and the Coeliac Trust for funding.

1 Rotter J, Landaw EM. Measuring the genetic contribution of a single locus to a multilocus disease. Clin Genet 1984; 26 : $529-42$.

2 Scholz S, Albert E. HLA and diseases: involvement of more than one HLA-linked determinant of disease susceptibility. Immunol Rev 1983; 70: 77-88.

3 Carroll MC, Katzman P, Allcot EM, et al. Linkage map of the human major histocompatibility complex including the tumor necrosis factor genes. Proc Natl Acad Sci USA 1987; 84: 8535-9.
4 Spies T, Blanck G, Bresnaham M, Sands J, Strominger JL. A new cluster of genes within the human major histocompatibility complex. Science 1989; 243: 214-7.

5 Sargent CA, Dunham I, Trowsdale J, Campbell RD. Human major histocompatibility complex contains genes for the major heat shock protein HSP70. Proc Natl Acad Sci USA 1989; 81: 1968-72.

6 Falchuck ZM, Rogentive N, Strober W. Predominance of histocompatibility antigen HLA-8 in patients with glutensensitive enteropathy. $\mathcal{F}$ Clin Invest 1972; 51: 1602-6.

7 Stokes PL, Asquith P, Holmes GKT, Mackintosh P, Cooke WT. Histocompatibility antigens associated with adult coeliac disease. Lancet 1972; ii: $162-4$.

8 Mann DL, Katz SI, Nelson DZ, Abelson LD, Strober W. Specific B cell antigens associated with gluten sensitive Specific B cell antigens associated with gluten sensitive
enteropathy and dermatitis herpetiformis. Lancet 1976; i: enteropat 110 .

9 DeMarchi M, Borelli I, Olivetti E, et al. Two HLA-DR alleles are associated with coeliac disease. Tissue Antigens 1979; 14 309-16.

10 Betuel H, Gebuhrer L, Descos L, Percebois H, Minaire Y Betrand J. Adult coeliac disease associated with HLADRw3 and DRw7. Tissue Antigens 1980; 15: 231-8.

11 Sachs JA, Awad J, McCloskey D, et al. Different HLA associated gene combinations contribute to susceptibility for coeliac disease and dermatitis herpetiformis. Gut 1986; 27 : 515-20.

12 Alper CA, Fleischnick E, Awdeh Z, Katz AJ, Yunis EJ. Extended major histocompatibility complex haplotypes in patients with gluten-sensitive enteropathy. $\mathcal{F}$ Clin Invest patients with g

13 Hitman A, Niven MJ, Festenstein H, et al. HLA class II alpha chain polymorphisms in patients with insulin dependen diabetes mellitus, dermatitis herpetiformis and celiac disease. F Clin Invest 1987; 79: 609-15

14 Gorski J, Niven MJ, Sachs JA, et al. HLA-DR $\alpha, D X \alpha$ and DR $\beta$ III gene association studies in DR3 individuals. Hum Immunol 1987; 20: 273-8.

15 Niven MK, Caffrey C, Sachs JA, et al. Susceptibility to coeliac disease involves genes in the HLA-DP region. Lancet 1987 ii: 805 .

16 Howell MD, Smith J, Austin RK, et al. An extended HLA-D region haplotype associated with celiac disease. Proc Natl Acad Sci USA 1988; 85: 222-6.

17 Woolf $B$. On estimating the relation between blood group and disease. Ann Hum Genet 1955; 19: 251-3.

18 Hyldig-Nielsen JJ, Morling N, Odum N, et al. Restriction fragment length polymorphism of the HLA-DP subregion and correlations to HLA-DP phenotypes. Proc Natl Aca Sci USA 1987; 84: 1644-8.

19 Howell MD, Austin RK, Kelleher D, Nepom GT, Kagnof MF. An HLA-D region restriction fragment length polymorphism associated with celiac disease. $\mathcal{F}$ Exp Med 1986 164: 333-8.

20 Termijtelen A, Bradley BA, van Rood JJ. A new determinant defined by PLT, coded for in the HLA region and apparently independent of the HLA-D and DR loci. Tissue Antigens 1980; 15: 267 .

21 Bodmer J, Bodmer W, Heyes J, et al. Identification of HLA DP polymorphism with DP $\alpha$ and DP $\beta$ probe and monoclonal antibodies: correlation with primed lymphocyte clonal antibodies: correlation with primed lymp

22 de Koster HS, Anderson DC Termijtelen AM.T cells de Koster HS, Anderson DC, Termijtelen AM. T cells
sensitized to synthetic HLA-DR3 peptide give evidence of continuous presentation of denatured HLA-DR3 molecules by HLA-DP. J Exp Med 1989; 169: 1191-6. 